\title{
The Trade-offs of Welfare Policies in Labor Markets with Informal Jobs: The Case of the “Seguro Popular” Program in Mexico
}

\author{
Mariano Bosch and Raymundo M. Campos-Vazquez
}

\section{ONLINE APPENDIX}

\section{Online Appendix A: Comparison between IMSS data and ENEU-ENOE data}

A series of studies analyze the impact of the SP using the Mexican labor survey. ${ }^{1}$ Before 2005 the labor force survey was called "Encuesta Nacional de Empleo-ENE", and from 2005 onwards was called "Encuesta Nacional de Ocupacion y Empleo-ENOE". This appendix compares our social security data, IMSS dataset, with the ENE-ENOE dataset.

Figure A.A.1 plots the evolution of total formal employment obtained in our dataset and total formal employment obtained from the ENE-ENOE dataset. The evolution of formal employment is very similar in both datasets. The number of formal jobs grew $11 \%$ in the ENEENOE dataset and $12 \%$ in the IMSS dataset (table A.A.1).

However, since the treatment of the SP is at the municipality level, the relevant geographical division is the municipality. There are three major advantages of the IMSS dataset compared to the ENE-ENOE dataset:

1) The ENE-ENOE dataset is not representative at the municipality level and hence formal employment level and growth are measured with substantial error, especially in small municipalities. Table A.A.1 (and figures A.A.2 and A.A.3) show the correlation of the growth rate of total formal employment from both datasets at the state level and at the municipality level between 2000 and 2009. At the state level we observe that there is substantial correlation between the growth rates in the IMSS and the ENE-ENOE data of around 0.67. However at the municipality level this correlation drops to 0.15 . We also report this statistic for four groups of municipalities depending on their size. As expected, the larger the municipality the higher the correlation. For municipalities with more than 300.000 inhabitants, the correlation is 0.48 , for small municipalities this correlation falls to 0.08. This highlights the lack of representativeness of small municipalities in the ENE-ENOE dataset.

\footnotetext{
${ }^{1}$ Campos-Vázquez and Knox (2010), Azuara and Marinescu (2011), Aterido, Hallward-Driemeier and Pages (2010) and Perez Estrada (2011).
} 
2) IMSS dataset has three times as many municipalities as the ENE-ENOE dataset. Whereas the ENE-ENOE only gathers data from around 426 municipalities, the IMSS dataset is available for 1392. This proves particularly important since the effects are mainly found in relatively smaller municipalities that are underrepresented in the ENE-ENOE.

3) There is a clear inconsistency in the merger between the ENE and ENOE in 2004-2005 of employment at the firm level. Although the overall formal employment trends seem to be smooth, as shown in figure A.A.1, we have been unable to reconcile the evolution of employment by firm size numbers. Table A.A.2 shows a table with the employment distribution by firm size in the ENE 2004q4 and the ENOE2005q4 obtained from the Mexican Statistical Institute (see link below). By their own account, there is a serious discrepancy with matching the data at the firm size level. The only category that seems to withstand the matching between the series is employment in firms with 1 to 5 workers (which also includes self-employment). For that particular level the share of formal jobs over total employment is below 5\%.

Table A.A.1. Correlations of Employment - ENE and IMSS data.

\begin{tabular}{lcc}
\hline & \multicolumn{2}{c}{$\begin{array}{c}\text { Number of } \\
\text { observations }\end{array}$} \\
\hline $\begin{array}{l}\text { Growth Formal } \\
\text { Employment 2000- }\end{array}$ & $11 \%$ & 1 \\
2009 ENE-ENEU & & \\
& & \\
Growth Formal & $12 \%$ & 1 \\
Employment 2000- & & \\
2009 IMSS & 0.67 & 32 \\
\hline Correlation state & & \\
level & & \\
& & \\
Correlation & 0.15 & 426 \\
municipality level & 0.48 & 51 \\
All & 0.14 & 84 \\
$>300.000$ & 0.10 & 96 \\
$>100.000-300.000$ & 0.08 & 195 \\
$50.000-100.000$ & & \\
$<50.000$ & & \\
\hline
\end{tabular}

Note: The table reports the correlation of the growth of formal employment at the country, state and municipality level between the administrative data (IMSS) and the household survey data ENE-ENOE. 
Table A.A.2: Employment by firm size.

\begin{tabular}{lrrrrr}
\hline & \multicolumn{1}{l}{ Total } & & Relative & \multicolumn{2}{c}{ Differences } \\
& ENE(2004) & ENOE(2005) & ENE(2004) & ENOE(2005) \\
\hline Total & 29.23 & 30.6 & $100.0 \%$ & $100.0 \%$ & $0.0 \%$ \\
1 to 5 & 11.23 & 12.02 & $38.4 \%$ & $39.3 \%$ & $0.9 \%$ \\
6 to 15 & 2.92 & 4.37 & $10.0 \%$ & $14.3 \%$ & $4.3 \%$ \\
16 to 100 & 4.46 & 6.59 & $15.3 \%$ & $21.5 \%$ & $6.3 \%$ \\
101 to 250 & 1.04 & 1.85 & $3.6 \%$ & $6.0 \%$ & $2.5 \%$ \\
251 and more & 9.53 & 5.2 & $32.6 \%$ & $17.0 \%$ & $-15.6 \%$ \\
Not Specified & 0.04 & 0.55 & $0.1 \%$ & $1.8 \%$ & $1.7 \%$ \\
\hline
\end{tabular}

Note: The table shows the employment levels by firm's size according to the last survey of the ENE in 2004 and the first survey of the ENOE in 2005.

http://www.inegi.org.mx/est/contenidos/espanol/metodologias/encuestas/hogares/sm_laboral.pdf

Figure A.A.1: Trends in formal employment: IMSS vs ENE-ENOE

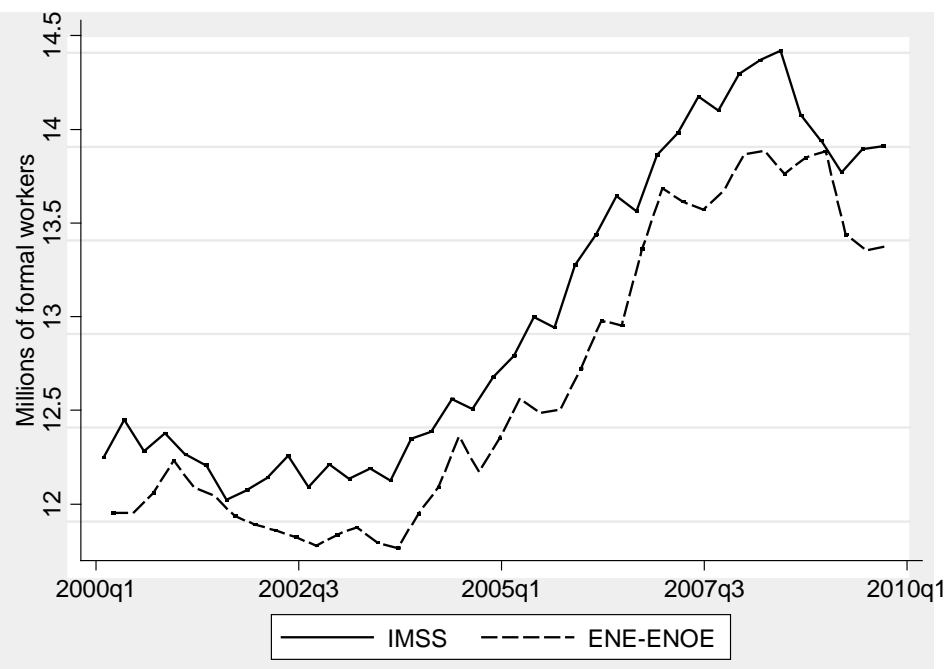


Figure A.A.2: Formal employment growth: Metropolitan areas in IMSS vs ENE-ENOE, 2000-2009.

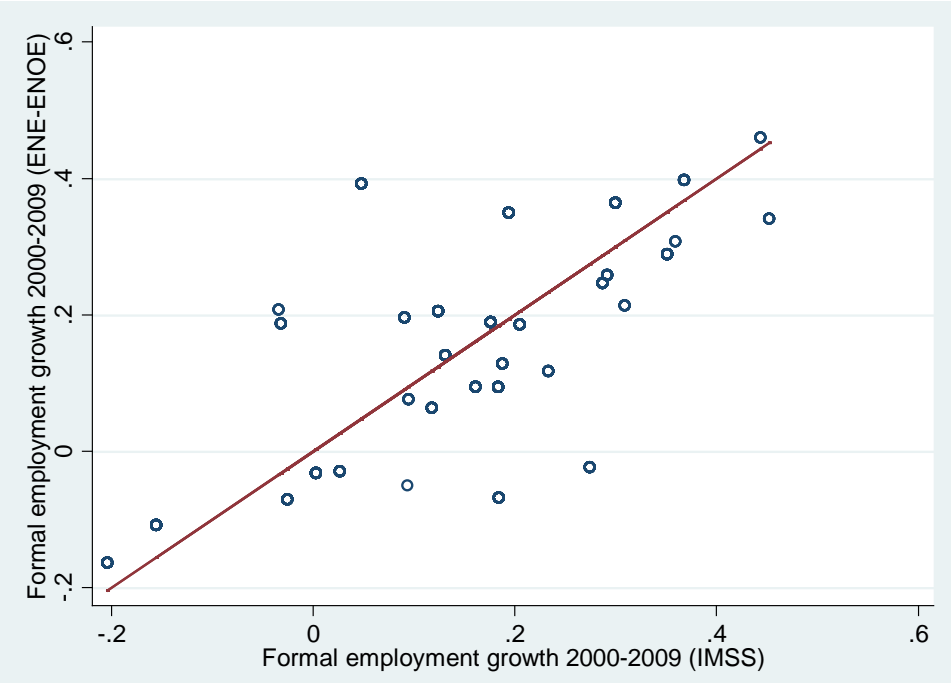

Figure A.A.3: Formal employment growth: Municipalities in IMSS vs ENOE, 20002009.

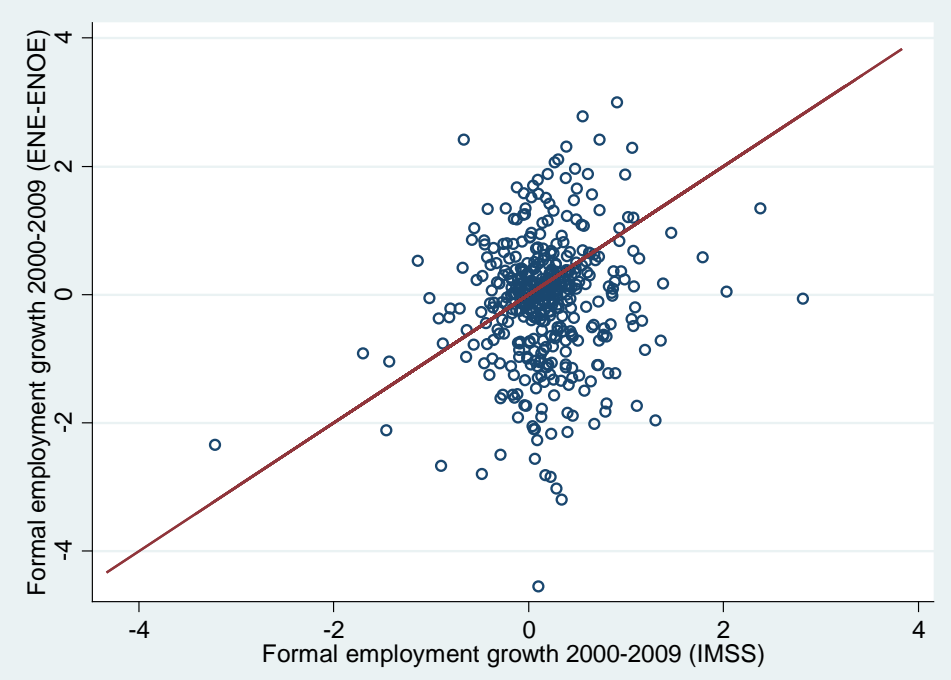




\section{Online Appendix B: Calculating the reallocation costs}

\section{I) Social security contributions loss}

This section calculates the revenue loss of displacing 171.000 workers from the formal to the informal sector.

For workers up to three minimum wages the contributions to social security for various items (health, old-age pensions, disability, accidents and day care centers are established as follows.

\section{Table A.B.1: Social Security Contributions}

\begin{tabular}{ll} 
Concept & Contributions \\
\hline Health and maternity & $20.40 \%$ of MW \\
Accident & $1.82 \%$ \\
Disability and life & $2.38 \%$ \\
Retirement & $6.28 \%$ \\
Day care centers & $1.00 \%$ \\
\hline Total & $31.87 \%$ \\
Source: IMSS, 2011 &
\end{tabular}

For workers earning more than 3 minimum wages there is an additional contribution for health equivalent to $1.5 \%$ of the difference between the wage and the minimum wage. In 2011 the distribution of workers in firms of less than 50 employees was

Table A.B.2: Distribution of workers in firms

\begin{tabular}{cc} 
Wage & $\begin{array}{c}\text { Share of } \\
\text { employees }\end{array}$ \\
\hline 1 MW & $5 \%$ \\
$1-2$ MW & $50 \%$ \\
$2-3$ MW & $20 \%$ \\
$>3$ MW & $25 \%$ \\
\hline
\end{tabular}

Source: IMSS, 2011

The loss in contributions is given by

$$
\Delta T s s=\bar{W} \times \bar{c} \times \Delta E
$$

Where $\bar{W}$ is the average annual wage of reallocated workers $\bar{C}$ is the average contribution rate of reallocated workers and $\Delta E=171.000$ 
We make three different assumptions about $\bar{W}$ and $\bar{c}$.

a) The employees reallocated were minimum wage employees. This is the most conservative estimate of contributions lost and constitutes a lower bound. No formal worker can be paid less than the minimum wage.

$$
\bar{W}=M W \text { and } \bar{c}=31.87 \%
$$

b) The employees reallocated were earning less than three minimum wages and are randomly selected according to the distribution in table A.B.2 (truncated at 3MW).

$$
\bar{W}=6 \% \times M W+68 \% \times 2 \times M W+26 \% \times 3 \times M W \text { and } \bar{c}=20.57 \%
$$

c) The employees reallocated were selected according to the distribution in table A.B.2

$$
\bar{W}=5 \% \times M W+50 \% \times 2 \times M W+20 \% \times 3 \times M W+25 \% \times 4.5 \times M W \text { and } \bar{c}=19.35 \%
$$

\section{II) VAT revenue loss.}

The Mexico's Economic Census measures economic activity taking place in private establishments with a fixed location and captures information on firm sales, value added, number of workers, types of contractual arrangements, labor remunerations, payments to IMSS, and value of fixed capital stock. Following Busso et al, 2013 we compute the value added of firms in Mexico in 2008 that have a least one formal employee, which are necessarily registered with IMSS. We then compute the loss in VAT revenue under the assumption that an addition $4 \%$ (see table 3 in the paper) of the firms between 1-50 employees would have been registered with IMSS. VAT in Mexico varies by product ranging from 0 to $16 \%$. We follow Levy (2008) who suggests that the average VAT is around $10 \%$. We present three alternative scenarios depending on different levels of compliance by formal firms, $100 \%, 50 \%$ and $25 \%$. Given the data measured in 2008 we inflation adjust the value added to 2011 prices.

The VAT loss given by

$$
\Delta T_{V A T}=\overline{Q_{i}} \times \Delta F
$$

Where $\overline{Q_{i}}$ is the average value added of a firm registered in the census with up to 50 employees and $\Delta F$ is the decrease in the number formal firms.

Calculations by firm size can be computed using table A.B.3. 


\section{Table A.B.3: Number of firms and value added}

\section{(For registered firms with at least 1 formal worker)}

\begin{tabular}{ccc} 
& $\begin{array}{c}\text { Value } \\
\text { Added } \\
\text { (Millions of } \\
\text { pesos) }\end{array}$ & $\begin{array}{c}\text { Number of } \\
\text { Firms }\end{array}$ \\
\hline$[0-5]$ & 76649 & 178075 \\
{$[6-10]$} & 75270 & 82409 \\
{$[11-50]$} & 259688 & 76946 \\
\hline Total & 411607 & 337430
\end{tabular}

\section{II) Output loss.}

The economy is populated by firms with Cobb-Douglass production function which, in logs, can be expressed as $\log (\mathrm{Qi})=\log (\mathrm{Ai})+\alpha \log (\mathrm{Li})+(1-\alpha) \log (\mathrm{Ki})$. The policy change generates an increase in informality, dI. If labor and capital are fixed then the change in firms value added would be equal to the change in productivity (i.e. $d \log (Q i) / d I=d \log (A i) / d I)$.

Busso, Fazio and Levy (2012) estimate that the productivity gap between formal-legal firms and informal-illegal firms for small firms is between 63 and 88 percent (see top panel, cols (1)(3) of Table 10). We can use these point estimates, assume that they are causal effects and combine them with the information presented in the bottom panel of Appendix Table 3, to compute the output loss (cost in terms of value added) for the private sector associated with a policy that induce $\mathrm{F}$ firms into informality.

In particular, the total output loss in the economy can be computed as:

$$
\Delta Q=\frac{d \log \left(Q_{i}\right)}{d I} \times \overline{Q_{i}} \times \Delta F
$$

Where $\overline{Q_{i}}$ is the average value added of a firm registered in the census with up to 50 employees.

Normalize the value added lost by the GDP in 2011.

Calculations by firm size can be computed using table A.B.3. 